\title{
A COMPARATIVE STUDY ON THE NUTRITIONAL CHARACTERISTICS OF MALE AND FEMALE CHINESE HOOK SNOUT CARP (OPSARIICHTHYS BIDENS)
}

\author{
CHEN, K. J. ${ }^{1 \#}-$ TANG, Y. ${ }^{\# \#}-$ LIU, D. Z. ${ }^{2 *}-$ GENG, B. ${ }^{1}-$ LIU, X. Y..$^{*}$ \\ ${ }^{1}$ College of Animal Science and Technology, Hunan Agricultural University, Changsha 420128, \\ China \\ ${ }^{2}$ Rural Agriculture Bureau of Taojiang County, Yiyang 413400, China \\ ${ }^{*}$ Corresponding authors \\ e-mail: 502732837@qq.com (Liu, D. Z); $1176450971 @ q q . c o m(L i u, X$. Y.) \\ ${ }^{\text {\# }}$ These authors contributed equally to this work.
}

(Received 24 $4^{\text {th }}$ Dec 2019; accepted $24^{\text {th }}$ Mar 2020)

\begin{abstract}
The nutritional composition of fish muscle is an important reference data for the design of fish feed formulae. However, the nutritional composition of the muscle of Chinese hook snout carp has not been analyzed at present. In addition, considering the obvious individual difference between male and female Chinese hook snout carp, there may also be significant difference in nutritional composition. To provide a reference for the feed formula design of artificially cultured Chinese hook snout carp, the muscle nutrient composition of five wild male and female individuals was analyzed in this study. Our results showed that water, crude protein, crude fat, and crude ash contents had no significant differences between male and female fish. Although there was no significant difference in the contents of most amino acids between male and female fish, the contents of flavored amino acids, essential amino acids and total amino acids in male fish muscle were significantly higher than those in female fish muscle. The proportion of saturated fatty acids, monounsaturated fatty acids, and polyunsaturated fatty acids was 1.37:1:1.80, and most of fatty acids showed significant difference between male and female fish.
\end{abstract}

Keywords: regional environment, culture method, feed, muscle nutrition, nutrient determination

\section{Introduction}

Chinese hook snout carp (Opsariichthys bidens Günther) is one of the most widely distributed small Asiatic cyprinids. It generally occupies fast-flowing mountainous steams (Perdices et al., 2005; Fu et al., 2012). However, due to habitat destruction caused by human activities and overfishing, the natural resources of the fish decreased dramatically in recent years (Chen, 2015).

To avoid extinction of wildlife resources due to over hunting, it is an important and feasible way to establish artificial breeding technology instead of the market demand for the wildlife resources (Chen, 2015; Xiang et al., 2018). For example, only in a Chinese county, Anhua County, $26505 \mathrm{~kg}$ of commercial adult Chinese hook snout carp and 994000 fries produced in 2012. However, although the nutritional composition of fish muscle is an important reference data for the design of fish feed formulae (Schaeffer et al., 2012), and a large number of studies have been reported on the nutritional composition of fishes (e.g. Hang et al., 2001; Xu et al., 2005; Lou et al., 2010; Liu et al., 2010; Yang et al., 2010), the nutritional composition of the muscle of Chinese hook snout carp has not been analyzed yet. In addition, considering the obvious individual difference between male and female of Chinese hook snout carp, there may also be significant difference in nutritional composition. 
The lack of nutritional composition of muscle seriously limits the development of feed formula and the efficiency of artificial propagation and cultivation of Chinese hook snout carp. For example, to provide more suitable feed for the parent fish of Chinese hook snout carp in the breeding stage, it is necessary to clarify the nutritional requirements of the male and female fish, and the muscle nutritional components of the male and female fish provide an important reference data for the development of such feed. To provide a reference for the feed formula design of artificial cultured Chinese hook snout carp, the muscle nutrient composition of wild male and female Chinese hook snout carp was analyzed in this study.

\section{Materials and Methods}

\section{Sample collection}

The Chinese hook snout carp samples were collected from Chetianjiang Reservoir, Anhua, China $\left(27.85^{\circ} \mathrm{N}, 111.60^{\circ} \mathrm{E}\right)$ on March 15 . The fish samples were transported to the laboratory by oxygenation and then fasted for 1 days. Each 5 male and female samples with the same size (approximately $50 \mathrm{~g}$ of each fish; Fig. 1) were selected and anesthetized $5 \mathrm{~min}$ using $100 \mathrm{mg} / \mathrm{L}$ of neutralized MS222 (tricaine methanesulfonate, Sigma-Aldrich, Germany) (Tuo et al., 2020). Then, the muscles on both sides of the back above the lateral scale below the dorsal fin were dissected for the determination of nutritional components.
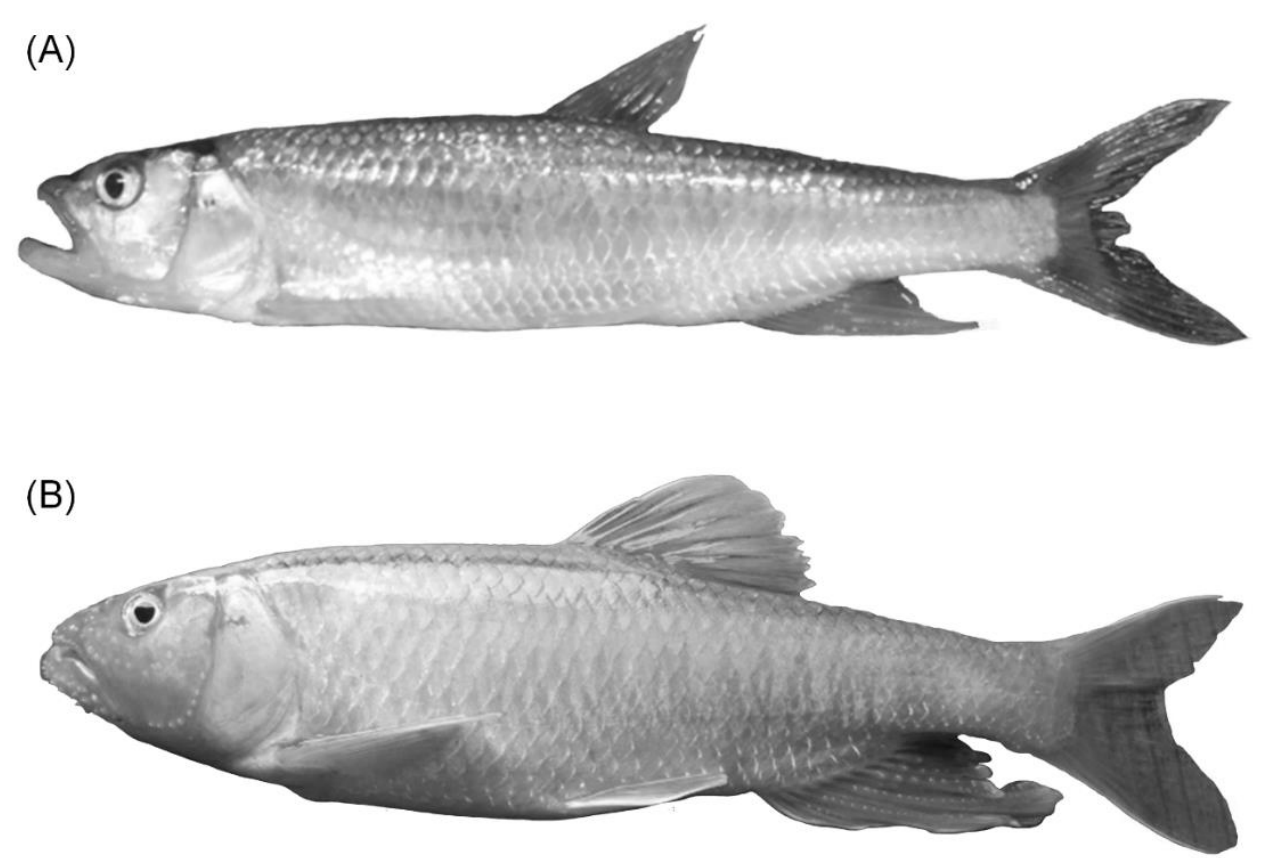

Figure 1. Photos of male (A) and female (B) Chinese hook snout carp

\section{Analysis of nutrients}

Dry matter content was determined by $105^{\circ} \mathrm{C}$ constant temperature and atmospheric pressure drying method. Crude protein content, crude fat content, and crude ash content was determined by Kjeldahl nitrogen method, Soxhlet extraction method, and muffle 
furnace burning method respectively according to previous studies (Saalah et al., 2010; Sun et al., 2011).

Amino acids were measured by a L8800 amino acid analyzer (Hitachi, Japan) (Sun et al., 2016). Fish oil was extracted by Soxhlet extraction (Ozogul et al., 2012). Composition of fatty acids was measured using a 6890-5973N gas chromatography - mass spectrometer (Agilent, USA) (Mazurek et al., 2017).

\section{Data analysis}

The data were showed as mean \pm standard deviation (S.D.) (Jiang et al., 2019). Independent $t$-test was conducted to test statistical difference between different groups using R software with basic packages (Everitt and Hothorn, 2010; Horton and Kleinman, 2011). Results with $\mathrm{p} \leq 0.05$ were considered statistically significant (Ni et al., 2019).

\section{Results}

Contents of the crude protein, crude fat, and crude ash in male Chinese hook snout carp muscles were $17.23 \pm 1.54 \%, 2.71 \pm 0.61 \%$, and $1.32 \pm 0.10 \%$, respectively. Contents of the crude protein, crude fat, and crude ash in female fish muscles were $16.71 \pm 0.99 \%, 2.23 \pm$ 0.92 , and $1.36 \pm 0.02 \%$, respectively (Fig. 2). Water content in muscle was no significant difference between the male and female fish (independent $t$-test, $t=0.90, p=0.38$ ). No significant difference of crude protein (independent $t$-test, $t=0.49, p=0.64$ ), crude fat (independent $t$-test, $t=1.38, p=0.18$ ), and crude ash (independent $t$-test, $t=1.20, p=0.25$ ) contents in muscle between male and female Chinese hook snout carp was found.

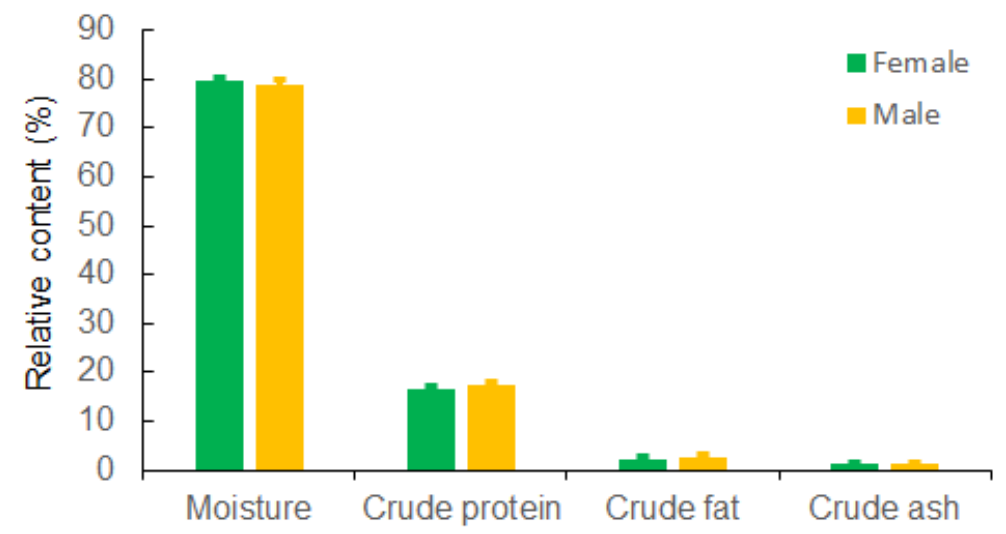

Figure 2. Nutritional compositions in muscle of male and female Opsariichthys uncirostris bidens Günther (\% wet weight)

Among the amino acids in the muscle of male and female Chinese hook snout carp samples, the highest amino acids were glutamic acid, proline, aspartic acid and lysine, all of which were more than $1.5 \mathrm{~g}$ in $100 \mathrm{~g}$ of muscle (Table 1). Only content of cystine in the muscle of male fish was significantly higher than that of female (independent $t$-test, $t=3.16$, $p=0.01$; Table 1). Although there was no significant difference in the contents of most amino acids between male and female fish, the contents of flavored amino acids, essential amino acids and total amino acids in male fish muscle were significantly higher than those in female fish muscle (Table 1). 
Table 1. The compositions and contents of amino acids in muscle of male and female Opsariichthys uncirostris bidens Günther

\begin{tabular}{|c|c|c|c|c|c|}
\hline Amino acid & Sampling size & Male (g/100 g) & Female $(g / 100 \mathrm{~g})$ & $t$ & $p$ \\
\hline Asp & 5 & $1.86 \pm 0.06$ & $1.86 \pm 0.07$ & 0.03 & 0.96 \\
\hline Ser & 5 & $0.78 \pm 0.02$ & $0.77 \pm 0.03$ & 0.62 & 0.55 \\
\hline Glu & 5 & $2.73 \pm 0.10$ & $2.65 \pm 0.06$ & 1.53 & 0.16 \\
\hline Ala & 5 & $1.04 \pm 0.03$ & $1.04 \pm 0.04$ & 0.02 & 0.98 \\
\hline Gly & 5 & $0.80 \pm 0.04$ & $0.79 \pm 0.05$ & 0.35 & 0.74 \\
\hline Arg & 5 & $0.98 \pm 0.04$ & $0.97 \pm 0.04$ & 0.40 & 0.70 \\
\hline Pro & 5 & $2.23 \pm 0.03$ & $2.23 \pm 0.03$ & 0.01 & 1.00 \\
\hline Cys & 5 & $1.28 \pm 0.01$ & $1.26 \pm 0.01$ & 3.16 & $0.01^{*}$ \\
\hline Tyr & 5 & $0.63 \pm 0.03$ & $0.62 \pm 0.02$ & 0.62 & 0.55 \\
\hline $\mathrm{NH}_{3}$ & 5 & $0.21 \pm 0.01$ & $0.21 \pm 0.01$ & 0.01 & 0.99 \\
\hline Val & 5 & $1.03 \pm 0.02$ & $1.02 \pm 0.02$ & 0.79 & 0.45 \\
\hline Met & 5 & $1.18 \pm 0.01$ & $1.16 \pm 0.02$ & 2.00 & 0.08 \\
\hline Ile & 5 & $0.86 \pm 0.01$ & $0.86 \pm 0.02$ & 0.01 & 0.99 \\
\hline Leu & 5 & $1.45 \pm 0.04$ & $1.44 \pm 0.04$ & 0.40 & 0.70 \\
\hline Phe & 5 & $1.09 \pm 0.01$ & $1.08 \pm 0.01$ & 1.58 & 0.15 \\
\hline Lys & 5 & $1.72 \pm 0.05$ & $1.72 \pm 0.05$ & 0.01 & 0.96 \\
\hline His & 5 & $0.60 \pm 0.01$ & $0.60 \pm 0.05$ & 0.16 & 0.88 \\
\hline Thr & 5 & $0.84 \pm 0.03$ & $0.84 \pm 0.04$ & 0.01 & 0.98 \\
\hline$\sum \mathrm{DAA}$ & 5 & $7.19 \pm 0.03$ & $7.10 \pm 0.01$ & 6.36 & $<0.001^{* * * *}$ \\
\hline$\sum \mathrm{EAA}$ & 5 & $8.76 \pm 0.01$ & $8.73 \pm 0.02$ & 3.00 & $0.02^{*}$ \\
\hline$\sum \mathrm{TAA}$ & 5 & $21.28 \pm 0.02$ & $21.11 \pm 0.02$ & 13.44 & $<0.001^{* * *}$ \\
\hline
\end{tabular}

$\sum$ DAA, flavored amino acid; $\sum$ EAA, essential amino acid; $\sum$ TAA, total amino acids. ${ }^{*} \mathrm{p}<0.05 ;{ }^{* *} \mathrm{p}<$ $0.01 ;{ }^{* * *} \mathrm{p}<0.001$

The saturated fatty acids detected in the muscle of the Chinese hook snout carp samples were c13:0, c14:0, c15:0, c16:0, c18:0 and c20:0. Methyl palmitate (c16:0) was the major saturated fatty acids, which accounted for $68.18 \%$ of the saturated fatty acids (Table 2). This result was similar to those reported in other fishes ( $\mathrm{Lv}$ et al., 1995). The main monounsaturated fatty acids were c16:1n-9 and c18:1, which accounted for $80.08 \%$ of the monounsaturated fatty acids (Table 2). The main polyunsaturated fatty acids were c22:6n-4, which accounted for $58.57 \%$ of the polyunsaturated fatty acids (Table 2). The proportion of saturated fatty acids, monounsaturated fatty acids, and polyunsaturated fatty acids was 1.37:1:1.80 (Table 2). Although the concentration distribution of various fatty acids in muscle of male and female fish was similar, the contents of most of fatty acids in muscle were significant differences between the male and female Chinese hook snout carp samples, in which c15:0 and c18:1 in male muscle were more than one time than those in female, while c27:2n-3 in female muscle was more than one time than that in male (Table 2). 
Table 2. The compositions and contents of ratty acids in muscle of male and female Opsariichthys uncirostris bidens Günther

\begin{tabular}{c|c|c|c|c|c}
\hline Fatty acid & Sampling size & Female (g/100 g) & Male (g/100 g) & $\boldsymbol{t}$ & $\boldsymbol{p}$ \\
\hline c13:0 & 5 & $0.50 \pm 0.03$ & $0.43 \pm 0.01$ & 4.95 & 0.07 \\
c14:0 & 5 & $1.86 \pm 0.05$ & $1.10 \pm 0.02$ & 31.56 & $<0.001^{* * *}$ \\
c15:0 & 5 & $2.35 \pm 0.03$ & $5.10 \pm 0.09$ & 64.82 & $<0.001^{* * *}$ \\
c16:0 & 5 & $19.35 \pm 0.45$ & $16.54 \pm 0.33$ & 11.26 & $<0.001^{* * *}$ \\
c16:1n-9 & 5 & $5.96 \pm 0.36$ & $6.55 \pm 0.28$ & 2.89 & $0.02^{*}$ \\
c18:0 & 5 & $4.11 \pm 0.03$ & $4.40 \pm 0.07$ & 8.51 & $<0.001^{* * *}$ \\
c18:1 & 5 & $10.68 \pm 0.57$ & $25.49 \pm 0.65$ & 38.31 & $<0.001^{* * *}$ \\
c18:2n-9 & 5 & $4.05 \pm 0.19$ & $7.77 \pm 0.32$ & 22.35 & $<0.001^{* * *}$ \\
c20:0 & 5 & $0.11 \pm 0.01$ & $0.18 \pm 0.01$ & 11.07 & $<0.001^{* * *}$ \\
c20:1n-9 & 5 & $0.35 \pm 0.02$ & $0.90 \pm 0.01$ & 55.00 & $<0.001^{* * *}$ \\
c20:1n-11 & 5 & $0.74 \pm 0.08$ & $1.18 \pm 0.07$ & 9.26 & $<0.001^{* * *}$ \\
c20:2n-11 & 5 & $1.11 \pm 0.08$ & $0.80 \pm 0.02$ & 8.41 & $<0.001^{* * *}$ \\
c20:4n-5 & 5 & $3.64 \pm 0.15$ & $3.35 \pm 0.12$ & 3.38 & $0.01^{* *}$ \\
c20:5n-5 & 5 & $1.93 \pm 0.12$ & $1.91 \pm 0.11$ & 0.27 & 0.79 \\
c22:6n-4 & 5 & $21.94 \pm 1.25$ & $17.17 \pm 1.75$ & 4.96 & $0.001^{* *}$ \\
c27:2n-3 & 5 & $6.72 \pm 0.45$ & $0.47 \pm 0.09$ & 30.45 & $<0.001^{* * *}$ \\
SFA & 5 & $28.38 \pm 1.69$ & $27.75 \pm 1.23$ & 0.67 & 0.52 \\
MUFA & 5 & $20.78 \pm 1.32$ & $33.70 \pm 1.75$ & 13.18 & $<0.001^{* * *}$ \\
PUFA & 5 & $37.46 \pm 2.11$ & $32.21 \pm 1.44$ & 4.60 & $0.001^{* *}$ \\
\hline
\end{tabular}

SFA, saturated fatty acids; MUFA, monounsaturated fatty acids; PUFA, polyunsaturated fatty acids. ${ }^{*} \mathrm{p}$ $<0.05 ;{ }^{* * *} \mathrm{p}<0.01 ;{ }^{* * *} \mathrm{p}<0.001$

\section{Discussion}

There is a close relationship between the nutritional composition of fish muscle and its feeding habits (Wang et al., 2010a). Generally, contents of crude protein and crude fat in muscle of carnivorous fishes are higher than those of herbivorous fishes, while the content of crude ash is lower than that of herbivorous fishes (Wang et al., 2010a). Our results showed that the content of crude protein in the Chinese hook snout carp was higher than that of yellow catfish (Pelteobagrus fulvidraco) (Jiang et al., 2013) and Qinling lenok (Brachymystax lenok) (Xu et al., 2010), lower than that of Phoxinus lagowskii (Zhang et al., 2013), and closed to that of Neosalanx brevirostris (Jiang et al., 2011) and other carnivorous fishes (Sun et al., 2008; Jiang et al., 2013). These results implied that the muscle of Chinese hook snout carp contained high protein level and conformed to its carnivorous attribute.

Sex is one of the most important factors that affect the composition of muscle nutrients in fish (Jiang et al., 2011; Zhang et al., 2013). Although contents of most of amino acids in muscle are significant difference between male and female Neosalanx brevirostris (Jiang et al., 2011) and Silurus asotus (Jiang et al., 2012), our results showed that only cystine content was significant difference between male and female Chinese hook snout 
carp, which was consistent with previous report in Pelteobagrus fulvidraco (Jiang et al., 2013). However, contents of most of fatty acids were significant differences in muscle between male and female Chinese hook snout carp, which was consistent with previous reports in Neosalanx brevirostris (Jiang et al., 2011).

Fish species is an important factor affecting the nutritional composition in muscle. Choi et al. (2008) reported that the protein in the muscle of Sophorae fructus is composed of a total of 18 different kinds of amino acids, and the contents of saturated fatty acids, monounsaturated fatty acids, and polyunsaturated fatty acids in the muscle of Sophorae fructus are $24.94 \%, 32.40 \%$, and $32.86 \%$, respectively. Our results showed that the contents of saturated fatty acids, monounsaturated fatty acids, and polyunsaturated fatty acids in the muscle of were $28.38 \%, 20.78 \%$, and $37.46 \%$, respectively. In addition, culture patterns, food sources and fish strains affect the compositions of fish nutrients (Wang et al., 2010b; Zhou et al., 2014).

\section{Conclusion}

In conclusion, contents of the crude protein, crude fat, and crude ash in male Chinese hook snout carp muscles were $17.23 \pm 1.54 \%, 2.71 \pm 0.61 \%$, and $1.32 \pm 0.10 \%$, respectively. Contents of the crude protein, crude fat, and crude ash in female fish muscles were $16.71 \pm 0.99 \%, 2.23 \pm 0.92 \%$, and $1.36 \pm 0.02 \%$, respectively. No significant difference of the crude protein, crude fat, and crude ash was detected between male and female fish. Although there was no significant difference in the contents of most amino acids between male and female fish, the contents of flavored amino acids, essential amino acids and total amino acids in male fish muscle were significantly higher than those in female fish muscle. The proportion of saturated fatty acids, monounsaturated fatty acids, and polyunsaturated fatty acids was 1.37:1:1.80, and most of fatty acids were significant difference between male and female fish. However, the influence of feed formulae designed according to our results on the reproduction and growth of Chinese hook snout carp should be further studied.

Acknowledgements. This research was supported by the Basic R \& D Project of Key R \& D Plan of Science and Technology Department of Hunan Province (No. 2015JC3104). The authors thank anonymous technicians at Guangdong Meilikang Bio-Science Ltd., China for assistance with data re-analysis.

\section{REFERENCES}

[1] Chen, C. (2015): Study on reproductive biological characteristics and breeding technology of Chinese hook snout carp (Opsariichthys bidens). - Changsha: Hunan Agricultural University.

[2] Choi, Y. S., Shin, E. H., Park, S. J., Kim, J. D. (2008): Nutritional characteristics and some bioactive components contents of Sophorae fructus. - Journal of the Korean Society of Food Science and Nutrition 37(9): 1154-1161.

[3] Everitt, B. S., Hothorn, T. (2010): A handbook of statistical analyses using R (Second edition). - CRC press, Boca Raton.

[4] Fu, S. J., Peng, Z., Cao, Z. D., Peng, J. L., He, X. K., Xu, D., Zhang, A. J. (2012): Habitatspecific locomotor variation among Chinese hook snout carp (Opsariichthys bidens) along a river. - PLoS ONE 7(7): e40791. 
[5] Hang, X., Tang, Y., Liu, X. (2001): Progress in the research on polyunsaturated fatty acids. - Progress in Biotechnology 21.

[6] Horton, N. J., Kleinman, K. (2011): Using R for data management, statistical analysis, and graphics. - CRC press, Boca Raton.

[7] Jiang, J., Han, X., Fu, Z., Sun, Z. (2011): Analysis and assessment of muscle nutritive composition between female and male Neosalanx brevirostris Pellegrin. - Journal of Guangdong Ocean University 31(4): 23-29.

[8] Jiang, J., Han, X., Fu, Z., Xie, G., Li, W., Meng, Y., Sun, Z. (2012): Comparative analysis of the main nutritional components in muscle and skin of male and female Silurus asotus. - Journal of Jimei University (Natural Science) 17(1): 6-12.

[9] Jiang, J., Fu, Z., Zhang, W., Li, W., Meng, Y., Sun, Z. (2013): Comparative analyses of the main nutritional components in edible tissues of male and female Pelteobagrus fulvidraco Richardson. - Journal of Bijie University 31(04): 96-103.

[10] Jiang, H., Liu, S., Xiao, T. Y., Cao, Y. K., Xie, M., Yin, Z. F. (2019): Cellular biological and eumelanin-related gene expressional bases of pigment deviation of Leptobotia taeniops. - Applied Ecology and Environmental Research 17(5): 12181-12189.

[11] Liu, Y., Xu, G., Mou, Z., Li, Y. (2010): Evaluation of nutritive quality and nutritional components of the muscle of Brachymystax lenok. - Acta Nutrimenta Sinica 32(1): 99-100.

[12] Lou, B., Gao, L., Mao, G., Shi, H., Luo, J. (2010): Analysis and Evaluation of the nutritional components in the muscle of Paralichthys olivaceus. - Acta Nutrimenta Sinica 32(02): 195-197.

[13] Lv, X., Li, M., Yao, Y., Gao, W., Yun, X., Kou, D. (1995): Preliminary analysis of fatty acid of some economical fishes. - Acta Scientiarum Naturalium Universitatis Nankaiensis 28(4): 20-25.

[14] Mazurek, B., Chmiel, M., Górecka, B. (2017): Fatty acids analysis using gas chromatography-mass spectrometer detector (GC.MSD) - method validation based on berry seed extract samples. - Food Analytical Methods 10(8): 2868-2880.

[15] Ni, J., Huang, R., Zhou, H., Xu, X., Li, Y., Cao, P., Zhong, K., Ge, M., Chen, X., Hou, B., Yu, M., Peng, B., Li, Q., Zhang, P., Gao, Y. (2019): Analysis of the relationship between the degree of dysbiosis in gut microbiota and prognosis at different stages of primary hepatocellular carcinoma. - Frontiers in Microbiology 10: 1458.

[16] Ozogul, Y., Şimşek, A., Balikçi, E., Kenar, M. (2012): The effects of extraction methods on the contents of fatty acids, especially EPA and DHA in marine lipids. - International Journal of Food Sciences and Nutrition 63(3): 326-331.

[17] Perdices, A., Sayanda, D., Coelho, M. M. (2005): Mitochondrial diversity of Opsariichthys bidens (Teleostei, Cyprinidae) in three Chinese drainages. - Molecular Phylogenetics and Evolution 37: 920-927.

[18] Saalah, S., Shapawi, R., Othman, N. A., Bono, A. (2010): Effect of formula variation in the properties of fish feed pellet. - Journal of Applied Sciences 10(21): 2537-2543.

[19] Schaeffer, T. W., Hennen, M. J., Brown, M. L., Rosentrater, K. A. (2012): Nutritional composition and use of common carp muscle in yellow perch diets. - North American Journal of Aquaculture 74: 297-305.

[20] Sun, Z., Li, C., Yin, H., Wang, B. (2008): Analysis of the nutritional composition in muscle of five varieties of Oncorhynchus mykiss. - Acta Nutrimenta Sinica 30(3): 298-302.

[21] Sun, H., Liu, X., Miao, Y. (2011): Speciation analysis of trace inorganic arsenic in dietary supplements by slurry sampling hydride generation atomic absorption spectrometry. Food Anal Methods 4: 251-257.

[22] Sun, J., Zhang, S., Hu, Q., Mao, X. H., Ji, S. (2016): Determination of 16 kinds of amino acids in health foods by high performance liquid chromatography with pre-column derivatization. - Journal of Food Safety \& Quality 7(7): 2715-2719.

[23] Tuo, Y., Xiao, T., Wang, H. (2020): Discrimination of sexual dimorphism through external morphology of Hemibarbus maculatus in the Yuanhe River, China. - Applied Ecology and Environmental Research 18(1): 1539-1550. 
[24] Wang, G., Sun, L., Li, Z., Guo, G., Niu, X., Lu, H. (2010a): Nutritional composition and evaluation in muscles and flesh content of various fishes with different feeding habits. Feed Industry Magazine 31: 94-98.

[25] Wang, J., Li, P., Song, Z., Wang, S., Li, B., Huang, B., Zhang, L. (2010b): Comparsion of amino acid composition in different tissues of the wild and the cultured Paralichthys olivaceus broodstock. - Journal of Fisheries of China 34(11): 1736-1743.

[26] Xiang, J., He, T., Wang, P., Xie, M., Xiang, J., Ni, J. (2018): Opportunistic pathogens are abundant in the gut of cultured giant spiny frog (Paa spinosa). - Aquaculture Research 49: 2033-2041.

[27] Xu, J., Zhu, Y., Yan, X., Ye, F., Xu, S. (2005): Comparison of fatty acids composition between farmed and wild yellow croaker Pseudosciaena crocea (Richardson). - Acta Nutrimenta Sinica 27(3): 256-257, 260.

[28] Xu, G., Ye, Y., Liu, Y., Mou, Z., Li, Y. (2010): Comparative analyses of nutritional composition in muscle of male and female lenok (Brachymystax lenok). - Chinese Journal of Fisheries 23(2): 29-33.

[29] Yang, P., Wang, Z., Xia, D., Li, M., Xie, C., Liu, L., Wang, W. (2010): Analysis of nutritional compositions and evaluation of nutritional quality of muscle of Aristichthys nobilis blackspot and Aristichthys nobilis whitespot. - Oceanologia et Limnologia Sinica 41(4): 549-554.

[30] Zhang, Y., Yin, J., Du, J., Geng, L., Bai, Q., Xu, W. (2013): Comparative analysis of nutritional compositions in muscle of female and male Phoxinus lagowskii Dybowski. Food Science 34(17): 259-262.

[31] Zhou, P., Jin, M., Wu, W., Shentu, J., Li, M., Zhou, Q. (2014): Comparison of nutrient components of large yellow croaker (Pseudosciaena crocea Richardson) cultured in different modes, fed different feeds and from different strains. - Chinese Journal of Animal Nutrition 26(4): 969-980. 